\title{
DESIGN AND SIMULATION OF NON-INVASIVE MICROWAVE ANTENNA FOR HYPERTHERMIA LIPOLYSIS SCHEME
}

\author{
Eman Yahya Elnady ${ }^{1 *}$, Kamel Hussein Rahouma ${ }^{1}$, and Hanfy M. Ali ${ }^{2}$ \\ ${ }^{1}$ Communication and Electronic Department, Electrical Engineering Department, Faculty of Engineering, Minia \\ University, El-Minia, Egypt \\ ${ }^{2}$ Computer and system Engineering Department, Faculty of Engineering, Minia University, El-Minia, Egypt \\ *Corresponding author Email: emy.yahya2030@ gmail.com
}

\begin{abstract}
A Non-invasive hyperthermia ablation technique of adipose tissue using a microwave is proposed. It uses dielectric heating to heat the adipose tissue using a rectangular Horn antenna. A selection of operating frequency $5.8 \mathrm{GHz}$, as an industrial, scientific, and medical radio bands (ISM band), for concentrating electromagnetic (EM) power radiated from the external antenna to the adipose tissue. To protect skin from heat, a silicon layer is used on the surface of the skin instead of water bolus to reduce the percentage of burns on the skin surface. The performance of this antenna is applied in three biological tissues (skin, fat, and muscles), using the simulation of computer simulation technology (CST) microwave studio. The main feature in this antenna is the centralization of the Specific absorption rate (SAR) at the fat tissue more than other tissues. Finally, results achieved good matching of the return loss (S11), and linear SAR value became high at fat tissue more than other tissues, and also the temperature distribution inside fat tissues became $42.7{ }^{\circ} \mathrm{C}$ while keeping the temperature inside the skin and muscles below $40{ }^{\circ} \mathrm{C}$ after 30 minutes.
\end{abstract}

Keywords: Non-Invasive Hyperthermia, Subcutaneous Tissues, Lipolysis, CST Microwave Studio, Horn Antenna, SAR. 


\section{INTRODUCTION}

Recently, the number of obese treatments has been gradually increased since more and more people have suffered from obesity due to many reasons in modern society such as lack of exercise, overeating, and so on. In recent years, non-invasive body contouring techniques have become one of the most widespread procedures. Although liposuction is extremely effective at removing large amounts of excess fat, it is accompanied by a significant risk of complications such as pain, swelling, prolonged recovery, scarring, hematoma, or infection, which makes non-invasive procedures increasingly preferred [1]. The ideal non-invasive fat treatment would safely and effectively "destroy or deactivate" fat cells non-invasive surgically for the long term, This has led to the development of non-invasive technologies based on high intensity focused ultrasound (HIFU), cryolipolysis, low-level lasers, and radiofrequency $(\mathrm{RF})$ [1]. One of the noninvasive methods is using RF the Electromagnetic waves for lipolysis and reduction of subcutaneous fat tissue. The lipolysis is accomplished with hyperthermia using microwave [2].

The main goal of this paper is to increase the temperature of fat tissue to temperature above $40^{\circ} \mathrm{C}$ for the lipolysis process; the apoptotic threshold is $42^{\circ} \mathrm{C}$. Adipocyte apoptosis results in the release of triglycerides from the disintegrated cell membranes, but in a delayed and gradual manner, enabling a slow and safe removal through the interstitial space, and subsequent

Received:19 October, 2020, Accepted:30 October, 2020 lipid transport systems, lymphatic and other metabolic functions [3]. Also, another goal is keeping skin and muscle below $42^{\circ} \mathrm{C}$ to protect them from burns.

To reach this goal, a specific design for a pyramidal horn antenna and phantom model is performed, as shown in fig.2. A pyramidal waveguide antenna was designed at 5.8 $\mathrm{GHz}$, as its equations are taken from [4]. The Horn antenna is propagating and radiating the electromagnetic waves for transverse electric mode (TE10) to generate temperature distribution over the area in fat tissue. The TE10 mode is discussed in [5]. The simplified phantom body model consists of three layers, skin, fat, and muscle, whose thickness was assumed to be $2 \mathrm{~mm}, 15 \mathrm{~mm}$, and $30 \mathrm{~mm}$, respectively. The thickness of these tissues is taken as a reference as it is mentioned in the more related paper in $[6,7$, and 8$]$.

During the design process, the simplified phantom tri-layered tissue model interfaced with a silicon pad layer instead of a water bolus layer with a thickness of $1 \mathrm{~cm}$ between the antenna and the phantom model to compensate for the stability of the return loss S11 between the antenna and the phantom and it is revealed on linear SAR simulation, as shown in fig. 4. Also, a silicon layer is used for the elimination of hot spots on the skin during hyperthermia treatment, as mentioned in [9].

This paper includes 5 sections, section 1 is the introduction, section 2 is the literature review, section 3 is the methodology, 
section 4 is the results and discussions, and section 5 is the conclusions.

\section{LITERATURE REVIEW}

For many years, microwave radiators have been used for hyperthermia treatment in many medical areas such as cancer treatment, muscle therapies, and lipolysis. In hyperthermia treatment, the most biological tissues are damaged or dead at a temperature over $40^{\circ} \mathrm{C}$ [10]. In the case of cancer treatment, the cancer cells can be killed by raising the cell temperature to over $42^{\circ} \mathrm{C}$ [11]. The muscle treatment can be done by stimulating the muscle with a temperature of above $41^{\circ} \mathrm{C}$ [12]. Also lately, several different treatment options of non-invasive technologies have been developed like highintensity focused ultrasound (HIFU), cryolipolysis, low-level lasers, and radiofrequency (RF) [13]. These devices have emerged as a popular alternative to surgical body contouring due to their efficacy, favorable safety profile, and minimal recovery time, and little cost. Although they do not achieve the same results as liposuction, they are an attractive alternative for patients who do not want the risks or costs associated with surgery [14].

First, the treatment method of non-invasive fat reduction is using High-Intensity Focused Ultrasound (HIFU devices) for reducing adipose tissue and body contouring [15]. Ultrasound devices for body contouring have been designed for skin tightening and fat reduction using acoustic energy. High-intensity focused ultrasound (HIFU) when focused at a targeted depth of 1.1 to $1.6 \mathrm{~cm}$ within subcutaneous tissue raises local tissue temperature at the focal point resulting in almost immediate cell death without damage to the surrounding tissues [16]. There are several different high-intensity focused ultrasound devices, the most popular of which is Ultherapy® (Merz Aesthetics, Raleigh, NC, USA). HIFU generates heat at the target sites that are attached to the external transducer. This heat induces necrosis of the adipocytes and stimulates collagen remodeling within the tissue matrix. Tissue temperatures above $56^{\circ} \mathrm{C}$ facilitate the necrotic process whilst avoiding the surrounding nerves and vessels [14]. Targeting both fat and collagen leads to gradual skin tightening and reduced adipose tissue. A short-duration approach helps ensure minimal epidermal damage. Each procedure lasts for approximately 3090 min, depending on the treatment location on the body. Common side effects include erythema, localized pain, swelling, and mild bruising, all of which typically resolve within hours to days [17]. (Chang et al. 2013) used Ultra Shape Contour I (HIFU) and RFVacTM (RF) from 2 weeks to 6 weeks in the Abdomen area, the results of this method is the circumference reduced by about $3.91 \mathrm{~cm}$ Fat thickness, 21.4\% (upper abdomen), $25 \%$ (lower abdomen). On another hand,( Shek et al. 2014) used Liposonix (HIFU) for a Single treatment (46.3 min) in the Abdomen area, the results of this method are the circumference reduces about $1 \mathrm{~cm}$ fat thickness [13].

Second, another treatment method of noninvasive by using Cryolipolysis, Cryolipolysis is one of the newest procedures for non-invasive fat reduction; the principle of cryolipolysis is based on the higher sensitivity of adipocytes towards cold 
in comparison with other cells. Cryolipolysis was effective in reducing adipose tissue, and also patient satisfaction was high after the treatment session [18]. It uses controlled cooling to specifically target areas of adipose tissue whilst preserving surrounding structures such as the overlying skin, muscles, and nerves. The most commonly used cryolipolysis device, Cool sculpts ${ }^{\circledR}$ (ZELTIQ Aesthetics, Inc., Pleasanton, CA, USA). A vacuum is used to suction adipose tissue into an applicator cup in which the fat is frozen between two cooling panels. The cold-initiated damage triggers panniculitis, which selectively induces apoptosis of the adipocytes without damaging surrounding tissues. The destroyed fat is then cleared by macrophages. This inflammatory process peaks at 2 weeks, but lasts for approximately 3 months and is accompanied by a progressive decline in fat thickness [14]. After a cryolipolysis session, patients should expect some mild temporary bruising, swelling, and sensory changes that usually resolve within days or weeks [19]. Results may first be noticed 3 weeks after starting treatment, but improvements may continue for up to 6 months. Cryolipolysis is not recommended in patients who are obese, have amorphous fat, have had previous abdominal hernia surgery, or suffer from cold-induced metabolic disorders. Cryolipolysis has been proved to be safe in any skin condition either light or dark skin type. There was no report of pigmentary changes after the treatment. Furthermore, some studies have revealed that there were no significant changes in lipid profiles and liver function tests within 12 weeks after cryolipolysis [20]. (Garibyan et al. 2014) used Zeltiq System (Cryolipolysis) for Single treatment (60 mints) in the flank area; the results produced a Fat thickness reduction of $14.9 \%$. Further, (Sasaki, Abelev, and Tevez-Ortiz 2014) used Zeltiq System (Cryolipolysis) for a Single treatment (60 mints) in multiple sites; the results produced a Fat thickness reduction of 27\% (abdomen), 25\% (hip) [13].

Third, there is another treatment method of non-invasive fat reduction by using LowLevel Laser therapy. Laser therapy is a relatively new, efficacious, and safe option for patients seeking modest non-invasive body contouring. Applying LLLT for fat removal has no observable consequence on surrounding tissues and does not increase tissue temperature. Moreover, it takes time to show its effect on the treated zone [21]. There are two types of devices currently exist. The older version, low-level laser therapy, was FDA-cleared in 2010 for fat reduction in the abdomen, back, thigh, and submental area. Low-level laser therapy uses a $635 \mathrm{~nm}$ wavelength to create temporary microscopic openings within the cell membrane of adipocytes, allowing lipids to leak out [14]. The lack of adipocyte cell death led to concerns regarding the permanency of low-level laser therapyinduced fat reduction. A 1060-nm diode laser has recently been developed that seeks to reduce adipose tissue through a thermally induced inflammatory process that is reminiscent of cryotherapy (SculpSure ${ }^{\circledR}$; Cynosure, Westford, MA, USA). Fifteen minutes of prolonged hyperthermia exposure selectively raises adipose tissue temperature to between 42 and $47^{\circ} \mathrm{C}$. A prototype diode laser system was developed utilizing four 
$1,060 \mathrm{~nm}$ diode bars directly coupled into a treatment handpiece [22]. This disrupts the cell membrane integrity to a degree that triggers apoptosis, after which the destroyed cells are eventually cleared from the interstitial space. The specificity of the 1060 $\mathrm{nm}$ wavelength combined with the device's contact cooling system ensures the preservation of the overlying skin during treatment [14]. The output could be adjusted with irradiance up to $5 \mathrm{~W} / \mathrm{cm} 2$ and pulse durations from $100 \mathrm{~ms}$ to continuous [22]. Low-level laser therapy sessions typically last up to $30 \mathrm{~min}$. The $1060-\mathrm{nm}$ laser treatments are slightly shorter, lasting between 20 and $25 \mathrm{~min}$. There are no reports of skin burns, scarring, or pigmentation changes. Swelling, tenderness, and induration may occur in some cases, but these undesirable outcomes typically resolve spontaneously within $1-3$ weeks. Results are best seen after 3 months, but improvements may be seen in half this time [23]. Laser treatment should be avoided in patients with a scar or tattoo at the treatment site, pregnant women, and those with an abdominal hernia or implanted metal. (McRae and Boris (2013)) used Erchonia Zerona (635 nm LLLT) for 1 session/week for 6 weeks, each session about 30 minutes. It is applied in Waist, hips, and thighs areas; the results produced the Circumference reduced by $2 \mathrm{~cm}$ (waist), $1.95 \mathrm{~cm}$ (hips), and $2.97 \mathrm{~cm}$ (thighs). Additionally, (Savoia et al. (2013)) used Vibro Light TM $(635 \mathrm{~nm}$ LLLT + Vibration) for 3/week for 2 weeks, each session about 40 minutes. It is applied in Abdomen, flanks, thighs, or buttocks; the results produced the Circumference reduced by $6.83 \mathrm{~cm}$ (abdomen and flanks), $3.42 \mathrm{~cm}$ (thighs), and $6.16 \mathrm{~cm}$ (buttocks) [13].

Fourth, another treatment method of noninvasive fat reduction by using Radiofrequency, RF is commonly used for increasing deeper skin temperature without any epidermal or dermal ablation. It is not only used as an efficient method for contracting or inducing skin tightening but also as an effective method for reducing fat [24]. Based on the principle of volumetric heating and the varied impedance of different skin layers, radiofrequency energy is used to generate heat that selectively targets the collagen-rich tissue layers to contract and denature collagen fibers, which results in immediate skin improvement. The thermal injury also induces apoptosis of adipocytes, which is responsible for the fat reduction component of the treatment [14]. $\mathrm{RF}$ treatment required about 35 minutes of average treatment time for the abdomen and 25 minutes of that for the thigh [25]. Posttreatment, plenty of water intakes were advised. No other special care was advised. The efficacy and safety of a novel radiofrequency for lipolysis, circumference reduction, treatment of skin laxity, and cellulite are very acceptable [25]. (Fajkosov an et al. 2014) used Vanquish ${ }^{\circledR}$ (RF) which is a monopolar radiofrequency device that has been developed primarily for fat reduction in the midsection including the abdomen, back, and flanks, and can cover very large treatment areas at one time through the unique use of extendable paddles. It is applied for $1 /$ week for 4 weeks, each session about 30 minutes. It is applied in the Abdomen area; the results of Circumference reduction reduced by 4.93 
cm. Further, (Boisnic et al. 2014) used BodyFX $®(R F+$ suction) for $1 /$ week for 6 weeks in the Abdomen area; the results of Circumference reduction of about $1.9 \mathrm{~cm}$. on the other hand,(Adatto, Adatto-Neilson, and Morren 2014) used VelaShape II ${ }^{\circledR}$ (RF, IR and mechanical) for $1 /$ week for 6 weeks in Multiple sites; the results of Circumference reduction about $1.4 \mathrm{~cm}$ (abdomen/flanks), $1.2 \mathrm{~cm}$ (thighs), $0.5 \mathrm{~cm}$ (buttocks) [13]. Radiofrequency sessions typically involve heating an area between $43 \mathrm{oC}$ and $45^{\circ} \mathrm{C}$, over 20-30 min followed by air-cooling of the epidermis with the device's built-in cryogen spray which creates a reverse thermal gradient. This cooling process is critical to protect the skin from complications such as burns, infections, and scarring changes [14]. So Microwave is used to reduce subcutaneous fat without burning the skin as a non-invasive solution to prevent obesity that may lead to diabetes, hyperlipidemia, arthritis, etc.

\section{METHODOLOGY}

The hyperthermia lipolysis can be done by increasing the temperature of subcutaneous adipose tissue above $40^{\circ} \mathrm{C}$, as it is mentioned in [2, 26, and 27]. For reduction, the subcutaneous fat tissues, the electromagnetic energy outside the body are used by an antenna to transmit an electromagnetic field to the fat under the skin to generate heat at the fat itself to melt it. Because of skin on the side of Microwave energy to transmit from the antenna to the fat, for that, the skin must be heated by the electromagnetic energy since the skin has higher relative permittivity than the fat has as is shown in table $1[28,29]$.
Thus, the skin absorbs electromagnetic waves more than fat; these results prove that the temperature of the skin is higher than that of fat under microwave radiation from outside. Then, it is necessary to prevent any thermal damage to the skin. So In this system, a silicon layer is used as an external material instead of water-bolus to reduce the percentage of skin burns [9]. So the skin temperature is not exceeding a certain temperature $\left(43^{\circ} \mathrm{C}\right)$.

For selecting the frequency band, Fig. 1 shows the absorbed power of the fat layer to incident power ratio versus operating frequency [27]. As shown in fig. 1 the absorbed power by fat tissue is maximum around $5 \mathrm{GHz}$, so the selection of $5.8 \mathrm{GHz}$ as the operating frequency, and also because $5.8 \mathrm{GHz}$ is one of the ISM bands [2].

Table 1: The electrical properties of skin, fat, and muscle tissues at $5.8 \mathrm{GHz}[28,29]$

\begin{tabular}{|c|c|c|c|}
\hline Tissue & $\begin{array}{c}\text { Relative } \\
\text { permittiv } \\
\text { ity, } \boldsymbol{\varepsilon}_{\mathbf{r}}\end{array}$ & $\begin{array}{c}\text { Conducti } \\
\text { vity, } \\
\text { (S/m) }\end{array}$ & $\begin{array}{c}\text { Loss } \\
\text { Tangen } \\
\mathbf{t}, \text { tan } \boldsymbol{\delta}\end{array}$ \\
\hline Skin & 38.62 & 4.3 & 0.34 \\
\hline Fat & 4.95 & 0.29 & 0.18 \\
\hline Muscle & 48.48 & 4.96 & 0.32 \\
\hline
\end{tabular}




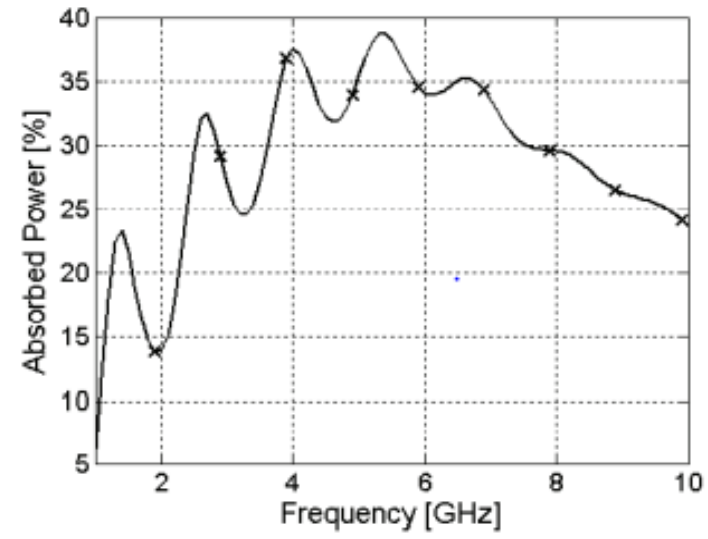

Fig. 1: The power absorbed in fat tissue.

\subsection{ANTENNA DESIGN}

To overcome this challenge, a specific design of pyramidal horn antenna that can be used in microwave non-invasive hyperthermia lipolysis without leaving any skin burns. The design consists of a pyramidal horn antenna and phantom model, as shown in fig.2. The pyramidal Horn antenna was designed at a single frequency at $5.8 \mathrm{GHz}$. The equations of this design are taken from [4]. Rectangular structures can be subdivided into H-plane, E-plane, and pyramidal horn structures (Balanis, 2005; Elliott, 2003). In this system, typically the pyramidal horn antenna is designed, which a schematic model is shown in Fig. 2, with the dimensions of the aperture rectangular guide feed to be $\mathrm{A} \times \mathrm{B}=145 \mathrm{~mm} \times 105 \mathrm{~mm}$ and a $\times \mathrm{b}=52.5 \mathrm{~mm} \times 22.5 \mathrm{~mm}$, respectively. The wall thickness is $2.5 \mathrm{~mm}$. Pyramidal horn antenna is a type of aperture antenna. The horn antenna is propagating and radiating electromagnetic waves for TE10 mode to generate temperature distribution inside the area of fat tissues more than other tissues. The TE10 mode is a type of microwave modes discussed in [5]. The horn antenna is constructed of aluminum for robustness, corrosion resistance, and high power sustainability.

The uniqueness of this design is that it is the first time to use a rectangular horn antenna for lipolysis, as in previous works; the design is about circular waveguide antenna. Also, this antenna structure is simple and easy to design and manufacture. Also, this antenna is coupled with a different material called silicon instead of water bolus as mentioned in other related researches in this field. Also, there isn't use for a cooling system, as it is an essential part of previous research in this area that makes the design is more complicated. Also, the antenna is coupling directly with the phantom model through a silicon layer that makes less power used in this system because of less waste of power. The simplified phantom body model consists of three planar layers (skin, subcutaneous fat, and muscle), whose thickness was assumed to be $2 \mathrm{~mm}, 15 \mathrm{~mm}$, and $30 \mathrm{~mm}$, respectively. The thickness of these tissues is taken as a standard here as it is repeated in the more related paper in $[6,7$, and 8]. The electrical properties of the three tissues mentioned before at $5.8 \mathrm{GHz}$ are shown in Table $1[28,29]$. Also, the thermal properties of the three tissues mentioned before are shown in Table 2 [30].

Another important part of a hyperthermia system is Water Bolus. Water Bolus as a cooling device, it is used to prevent skin damage in many of the available equipment in hyperthermia applicators. But it causes adverse effects on antenna radiations [31]. During the design process, the simplified 
phantom tri-layered tissue model interfaced with a water bolus. It was used to incorporate the main electrical effects of the antenna on the phantom model, but the results don't validate the proposed antenna design, because of mismatching in return loss. So a selection of a silicon pad layer instead of a water bolus layer is the best choice to compensate for the stability of reflection coefficient S11 between the antenna and the phantom model.

The difference from previous researches in the hyperthermia lipolysis field is that it is the first time to use this material called a silicon layer instead of a water bolus material between the antenna and the phantom model. The silicon layer material is used before but, for cancer hyperthermia treatment in muscle tissue [9]. Also, a silicon layer is used for the elimination of hot spots on the skin during hyperthermia treatment. Maybe the most important benefit of using a silicon layer instead of water bolus is exhibited in linear SAR simulation, as shown in fig. 4. After being informed of the reasons for the necessity of the silicon layer, now the thickness of that must be investigated. For this, a parametric sweep of the thickness of silicon is performed in CST software to get the best results in s11 and linear SAR. So the best thickness of a silicon layer is selected in coordination with S11 and linear SAR results, so its thickness about $1 \mathrm{~cm}$ between the horn antenna and the phantom model for best results in fig. 3 and fig. 4. The proposed antenna can make the highest temperature distribution inside the subcutaneous fat layer, which means that it expands an effective area for hyperthermia treatment. So it could be effective to treat subcutaneous fat of a wider area only with a single antenna. To minimize the spillover power of the antenna, the pyramidal waveguide antenna was designed for the use in contact with the skin directly.

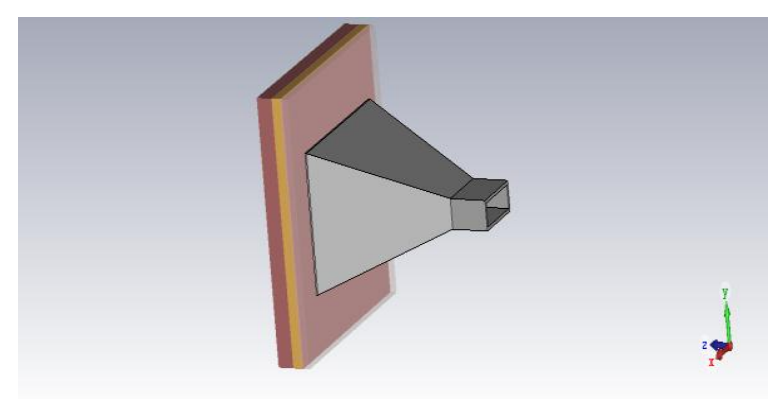

Fig.2: The horn antenna with phantom model

Table 2: The thermal properties of each tissue type [30]

\begin{tabular}{|c|c|c|c|}
\hline Tissue & $\begin{array}{c}\text { Mass } \\
\text { Density } \\
(\mathbf{k g} / \mathbf{m} 3 \\
)\end{array}$ & $\begin{array}{c}\text { Specific } \\
\text { Heat } \\
\left(\mathbf{J} / \mathbf{k g} /^{\mathbf{0}}\right. \\
\mathbf{C})\end{array}$ & $\begin{array}{c}\text { Thermal } \\
\text { Conductivity } \\
\left(\mathbf{W} / \mathbf{m} /{ }^{\mathbf{0}} \mathbf{C}\right)\end{array}$ \\
\hline Skin & 1100 & 3150 & 0.34 \\
\hline Fat & 910 & 2300 & 0.23 \\
\hline Muscle & 1041 & 3500 & 0.49 \\
\hline
\end{tabular}

\section{RESULTS AND DISCUSSIONS}

Simulation, analysis, and modification of the design parameters were performed using commercial CST microwave studio software as a simulation tool. The performance of the antenna is investigated with only a silicon pad. The best height of the silicon pad is selected in coordination with S11 and linear SAR results. Then the best height of the silicon pad is $10.5 \mathrm{~mm}$ for good matching in return loss S11 and linear SAR inside fat tissue. The Horn applicator is fed with 0.5 
$\mathrm{W}$ and applied on to the phantom model for $3000 \mathrm{Sec}$.

Fig. 3 shows simulated return loss S11 of the antenna with the phantom model. As shown in fig. 3 there is a good matching between the horn antenna and phantom model at $5.8 \mathrm{GHz}$. The Linear SAR value of the EM wave inside fat tissue in the phantom model is $2.2 \mathrm{~W} / \mathrm{kg}$, which is compatible with the regulated SAR limitation (>0.5 W/kg) of the IEEE standard for local hyperthermia applications. The SAR value is shown in fig. 4.

Also by using the CST simulation program, by using a thermal solver inside it to present the temperature distribution inside the phantom model at $5.8 \mathrm{GHz}$, as shown in fig. 5. The temperature started from $37^{\circ} \mathrm{C}$ and after 30 minutes, the temperature inside fat tissue rises above $42^{\circ} \mathrm{C}$. This means that affecting fat tissues causing lipolysis of the subcutaneous fat that leads to apoptosis of these tissues. Adipocyte apoptosis results in the release of triglycerides from the disintegrated cell membranes. This disrupts the cell membrane integrity to a degree that triggers apoptosis, after which the destroyed cells are eventually cleared from the interstitial space. The destroyed fat is then cleared by macrophages [14]. Also, it is confirmed that the skin temperature does not rise higher than the fat temperature, as shown in fig. 6. The temperature of the skin and muscle tissues is still below $40^{\circ} \mathrm{C}$ after 30 minutes.

AS compared with other papers in this field, getting a high temperature at fat tissue above $40^{\circ} \mathrm{C}$, plus keeping the temperature at skin and muscle below $40^{\circ} \mathrm{C}$ without using a cooling system, as it is discussed in [2, 27]. Also, these results are acceptable without using the external heat sink, as it is discussed in [26]. This work is about design a horn antenna which is a simple design and using a silicon pad as an external material used in skin cooling and to prevent hot spots on it. This material is simple and cheap. A comparison of electromagnetic characteristics of the proposed antenna and previous work are shown in table 3 .

Fig. 3: Return loss of the pyramidal horn antenna

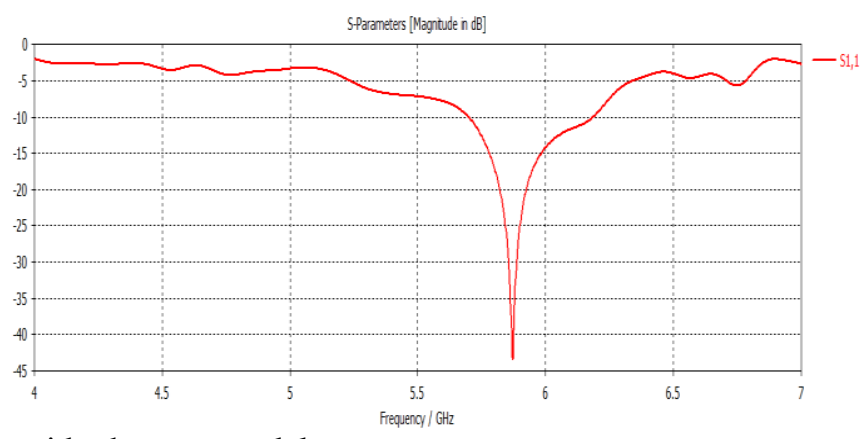

with phantom model

Fig. 4: SAR value at the three-layer phantom model

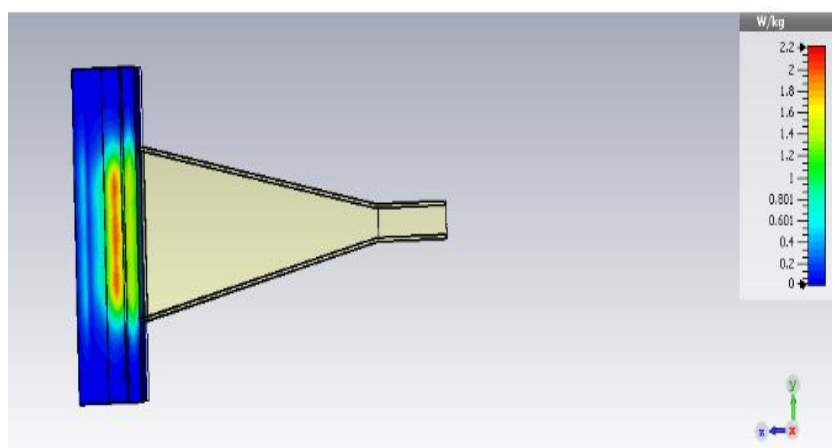

at $5.8 \mathrm{GHz}$

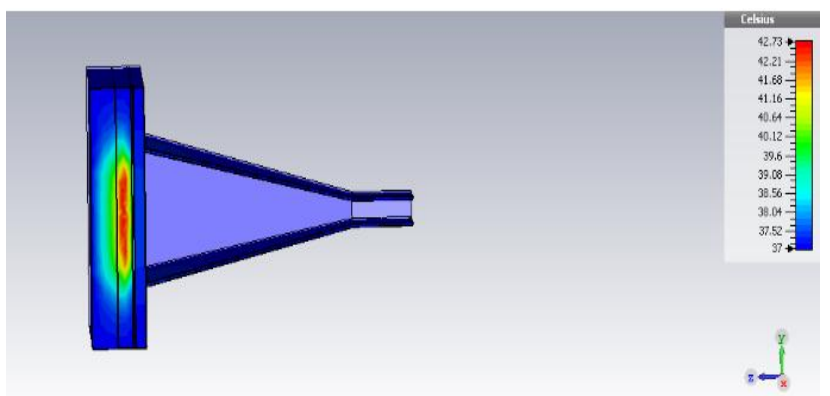

Fig. 5: The simulation result of the temperature 


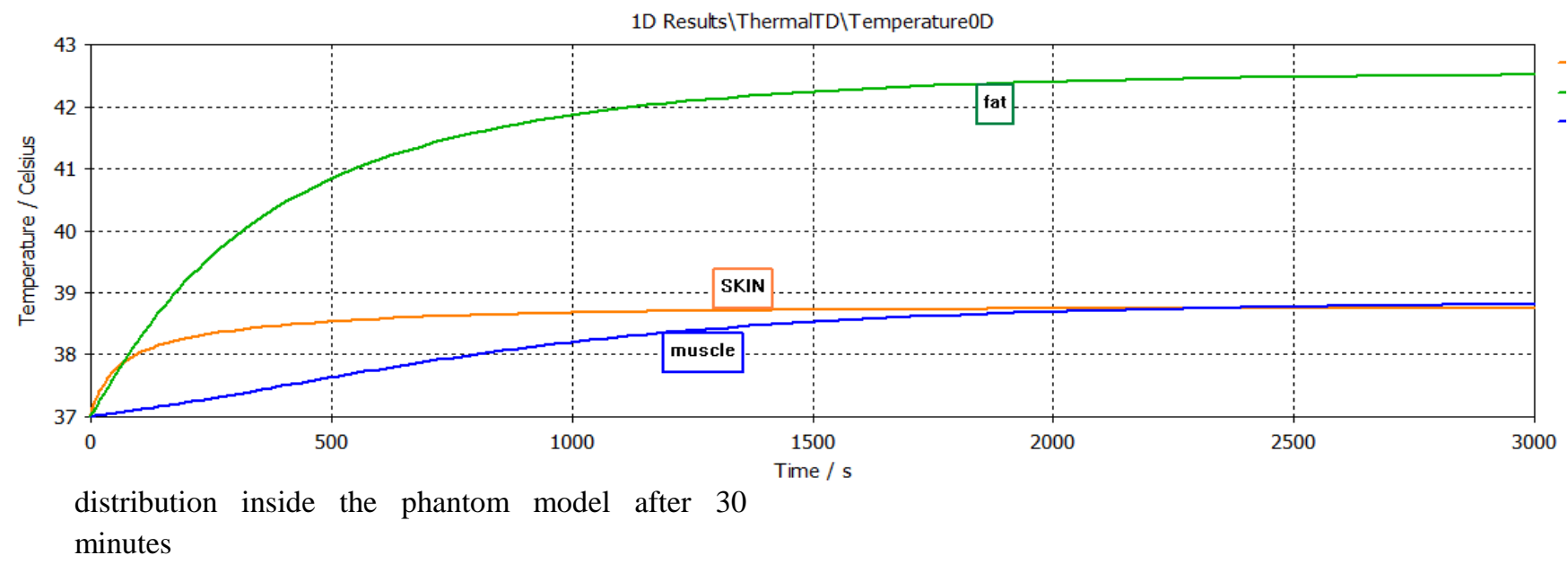

Fig. 6: The temperature inside the phantom model (skin, fat, and muscle) versus time

Table3:Comparison of electromagnetic characteristics of the proposed antenna and previous works

\begin{tabular}{|c|c|c|c|}
\hline Parameters & $\begin{array}{l}\text { This } \\
\text { work }\end{array}$ & [2] & [26] \\
\hline $\begin{array}{c}\text { Frequency } \\
\text { (GHZ) }\end{array}$ & $\begin{array}{c}5.8 \\
\mathrm{GHz}\end{array}$ & $\begin{array}{c}5.8 \\
\mathrm{GHz}\end{array}$ & $\begin{array}{l}7.875 \\
\mathrm{GHz}\end{array}$ \\
\hline $\begin{array}{l}\text { Return Loss } \\
\text { (dB) }\end{array}$ & $-18 \mathrm{~dB}$ & $\begin{array}{c}\text { Not } \\
\text { availa } \\
\text { ble }\end{array}$ & $-22 \mathrm{~dB}$ \\
\hline SAR [W/kg] & $\begin{array}{c}2.2 \\
\mathrm{~W} / \mathrm{kg}\end{array}$ & $\begin{array}{c}\text { Not } \\
\text { availa } \\
\text { ble }\end{array}$ & $\begin{array}{c}\text { Not } \\
\text { available }\end{array}$ \\
\hline $\begin{array}{l}\text { Temperature } \\
{ }^{\circ} \mathrm{C} \text { in fat } \\
\text { tissue after } \\
30 \text { min. }\end{array}$ & $42.5^{\circ} \mathrm{C}$ & $45^{\circ} \mathrm{C}$ & $42.5^{\circ} \mathrm{C}$ \\
\hline $\begin{array}{c}\text { Temperature } \\
{ }^{\circ} \mathrm{C} \text { in skin } \\
\text { tissue after } \\
30 \text { min. }\end{array}$ & $38.7^{\circ} \mathrm{C}$ & $42{ }^{\circ} \mathrm{C}$ & $39^{\circ} \mathrm{C}$ \\
\hline Power (W) & $0.5 \mathrm{~W}$ & $4 \mathrm{~W}$ & $3.3 \mathrm{~W}$ \\
\hline $\begin{array}{l}\text { Using cooling } \\
\text { system }\end{array}$ & no & yes & yes \\
\hline
\end{tabular}

\section{CONCLUSIONS}

In this paper, a simple design of pyramidal horn antenna for non-invasive microwave hyperthermia lipolysis is proposed without leaving any skin burns. An important modification of this paper is to replace the water bolus layer with a silicon layer due to its low weight and reduced harmful effects on body tissue. The disadvantage of the water bolus is its unpredictable and complex behaviors during treatment as well as its heavy structure making serious problems for hyperthermia antennas designers. The operating frequency has been selected for the RF power not to penetrate to the inner organ of the body but to penetrate fat tissues under the skin effectively. Also, it is in the ISM band. To prevent damages to the skin when the microwave power is applied by an external antenna, a silicon pad is developed to eliminate hot spots on the skin surface during hyperthermia. In future work, a modification will be added like using an external fan or conditioner to add more cooling for the skin. Finally, the simulation results give return losses S11, SAR, and thermal distribution which show a good electromagnetic performance of the 


\section{Vol.41, No. 1. January 2022}

proposed antenna based on IEEE standards, and also they are investigated for proposed concept confirmation. So lipolysis can be successfully performed using an external antenna. The results were compared with those of previous work of other researchers.

\section{REFERENCES}

[1] Zahra Alizadeh,Farzin Halabchi, Reza Mazaheri, Maryam Abolhasani, and Mastaneh Tabesh "Review of the Mechanisms and Effects of Non-invasive Body Contouring Devices on Cellulite and Subcutaneous Fat". Int J Endocrinol Metab. 2016 October; 14(4):e36727. DOI: 10.5812/ijem.36727, Published online 2016 July 3.

[2] Joosung Hwang, TaeHee Woo, Sangbok Park, Changyul Cheon, Youngseek Chung, Jeiwon Cho, Youngwoo Kwon, "A study on non-invasive hyperthermic lipolysis using microwave" , IEEE International Symposium On Antennas And Propagation And USNC/URSI National Radio Science Meeting, 2011.

[3] Sylvie Boisnic, Marc Divaris, Andrew A. Nelson, Nima M. Gharavi, and Gary P. Lask, "A Clinical and Biological Evaluation of a Novel, Non-invasive Radiofrequency Device for the Long-Term Reduction of Adipose Tissue". Lasers in Surgery and Medicine 46:94-103 (2014). DOI 10.1002/lsm.22223.

[4] Constantine A. Balanis, 'Antenna Theory', John Wiley \& Sons, 2005.

[5] David M. Pozar, Microwave Engineering, John Wiley \& Sons, 2005.

[6] S. Sarjoghian, Y. Alfadhl, and Xiaodong Chen, "A novel wide-band reflection-based system for measuring abdominal fat in humans," in URSI Int. Symp. Electromag. Theory (EMTS), pp. 586- 589, Aug. 2016.
[7] Noor M. ALBADRI, David V. THIEL, Hugo G. ESPINOSA, "Wearable Slot Antenna for Biomedical Applications: Mutual Coupling and External Interference", RADIO ENGINEERING, VOL. 29, NO. 2, JUNE 2020.

[8] Hemn Younesiraad, Mohammad Bemani, and Saeid Nikmehr, "A Dual-Band Slotted Square Ring Patch Antenna for Local Hyperthermia Applications", Progress In Electromagnetics Research Letters, Vol. 71, 97102, 2017.

[9]Saman Rajebi, Changiz Ghobadi,

Javad Nourinia, Ehsan Mostafapour "SAR Enhancement of Slot Microstrip Antenna by Using Silicon Layer in Hyperthermia Applications" (c) Springer Science+Business Media, LLC, part of Springer Nature 2019.

[10] Azeem Imtiaz , Hana Trefna, Claes Beckman, "Ultra-Wideband Antenna Array For Microwave Hyperthermia" Master's Thesis: 830905-8710 Department of Signals and System Group of Biomedical Electromagnetics Chalmers University of Technology SE-41296 Gothenburg, Sweden. Gothenburg, September 2010 .

[11] Maha R. Abdel-Haleem, Tamer Abouelnaga, Sabah M. Ahmed, Mohammed Abo-Zahhad, "Convex Lenses Horn Antenna Microwave Hyperthermia Scheme", 12th European Conference on Antennas and Propagation (EUCAP 2018).

[12] Noriko Ichinoseki-Sekine, and Shizuo Katamoto, "Effects of microwave hyperthermia at two different frequencies (434 and 2450 $\mathrm{MHz}$ ) on human muscle temperature," Journal of sports science and medicine, vol. 7, pp. 191193, March 2008.

[13] J. Kennedy, S. Verne, R. Griffith, L. FaltoAizpurua, K. Nouri "Non-invasive subcutaneous fat reduction: a review" (C) 2015 European 


\section{Vol.41, No. 1. January 2022}

Academy of Dermatology and Venereology. JEADV 2015, 29, 1679-1688. DOI: 10.1111/jdv.12994.

[14] Daniel Mazzoni, Matthew J Lin, Danielle P Dubin, Hooman Khorasani "Review of noninvasive body contouring devices for fat reduction, skin tightening and muscle definition" Australasian Journal of Dermatology (2019) 60, 278-283. Doi: 10.1111/ajd.13090.

[15] Mulholland RS, Paul MD, Chalfoun C. "Non-invasive body contouring with radiofrequency, ultrasound, cryolipolysis, and low-level laser therapy." Clin Plast Surg. 2011; 38(3):503-20. Doi: 10.1016/j.cps.2011.05.002. [PubMed: 21824546] vii-iii.

[16] Bishara S. Atiyeh, Fadl Chahine "EvidenceBased Efficacy of High-Intensity Focused Ultrasound (HIFU) in Aesthetic Body Contouring" Received: 16 May 2020 / Accepted: 28 June 2020 Springer Science+Business Media, LLC, part of Springer Nature and International Society of Aesthetic Plastic Surgery 2020.

[17] Ko EJ, Hong JY, Kwon TR et al. "Efficacy and safety of noninvasive body tightening with high-intensity focused ultrasound (HIFU)". Skin Res. Technol. 2017; 23: 558-62.

[18] Shek SY, Chan NP, Chan HH. "Noninvasive cryolipolysis for body contouring in Chinese-a first commercial experience". Lasers Surg Med. 2012; 44(2):125-30. Doi: 10.1002/lsm.21145. [PubMed: 22334296].

[19] Klein KB, Bachelor EP, Becker EV, and et al. multiple same day cryolipolysis treatments for the reduction of subcutaneous fat are safe. Lasers Surg. 2017; 49: 640-4.

[20] Imam Budi Putra , Nelva Karmila Jusuf, Nani Kumala Dewi "Utilisation of Cryolipolysis among Asians: A Review on Efficacy and
Safety", Open Access Macedonian Journal of Medical Sciences. 2019 May 15; 7(9):15481554.

https://DOI.org/10.3889/oamjms.2019.318.

[21] Savoia A, Landi S, Vannini F, Baldi "A. Low-level laser therapy and vibration therapy for the treatment of localized adiposity and fibrous cellulite." Dermatol Ther (Heidelb). 2013; 3(1):41-52. DOI: 10.1007/s13555-0130026-x. [PubMed: 23888254].

[22] John W. Decorato, Bo Chen, and Rafael Sierra, "Subcutaneous Adipose Tissue Response to a Non-Invasive Hyperthermic Treatment Using a 1,060 nm Laser" Lasers in Surgery and Medicine 49:480-489 (2017).

[23] Bass LS, Doherty ST. Safety and efficacy of a non-invasive $1060 \mathrm{~nm}$ diode laser for fat reduction of the abdomen. J. Drugs Dermatol. 2018; 17: 106-12.

[24] Weiss RA. "Non-invasive radiofrequency for skin tightening and body contouring". Semin Cutan Med Surg. 2013; 32(1):9-17. [PubMed: 24049924].

[25] Rinky Kapoora, Debraj Shomeb, and Anima Ranjane, "Use of a novel combined radiofrequency and ultrasound device for lipolysis, skin tightening and cellulite treatment", 2017, VOL. 19, NO. 5, 266-274 https://doi.org/10.1080/14764172.2017.1303169

[26] Sangbok Park, Joosung Hwang, Youngwoo Kwon, and Changyul Cheon, "A New Antenna System for Microwave Non-invasive Hyperthermia Lipolysis" 34th Annual International Conference of the IEEE EMBS San Diego, California USA, 28 August - 1 September 2012.

[27] Tae-Hee Woo, Minkyun Yoo, Wanghyun Kim, Youngwoo Kwon, Young-Seek Chung, 
Vol.41, No. 1. January 2022

Jeiwon Cho, and Changyul Cheon, "Noninvasive hyperthermic ablation of adipose tissue using a microwave," IEEE International Symposium On Antennas And Propagation And USNC/URSI National Radio Science Meeting, 2010.

[28] Noor Badariah Asan, Daniel Noreland, Emadeldeen Hassan, Syaiful Redzwan Mohd Shah, Anders Rydberg, Taco J. Blokhuis, PerOla Carlsson, Thiemo Voigt, and Robin Augustine, 2017. "Intra-body Microwave Communication through Adipose Tissue," Healthcare Technology Letters, 4(4), pp. 115121.

[29] Noor Badariah Asan, Emadeldeen Hassan, Mauricio D. Perez, Laya Joseph, Martin Berggren, Thiemo Voigt, and Robin Augustine.
2019. "Fat-Intra Body Communication at 5.8 $\mathrm{GHz}$ Including Impacts of Dynamic Body Movements" (manuscript).

[30] S. Curto, P. McEvoy, X. L. Bao, and M. J. Ammann, "Compact patch antenna for electromagnetic interactiol with hurlian tissue at $434 \mathrm{MHz}$," IEEE Transactions on Antennas and Propagation, vol. 57, no. 9, pp. 2564-2571, Sept. 2009.

[31] Koo, Y. S., Fathy, A., Kazemi, R., Liu, Q., \& Phillips, J. (2014). Development of a high SAR conformal antenna for hyperthermia tumors treatment. IEEE Transaction on Antennas and Propagation, 62, 5830-5840. 